\title{
Maternal Awareness of Pregnancy Normal and Abnormal Signs: An Exploratory Descriptive Study
}

\author{
Hadayat A. Amasha, Manar F. Heeba \\ Department of Obstetric \& Gynecological Nursing, Faculty of Nursing, Port Said University, Egypt
}

\begin{abstract}
Most pregnant women complain to some degree of minor discomfort. These discomforts are not serious in themselves, but their presence detracts from the mother feeling of comfort and wellbeing. Maternal morbidity and mortality could be prevented significantly if women recognize abnormal signs and promptly seek health care. Aim: The main aim of this study was to evaluate Jordanian women's awareness of pregnancy normal and abnormal signs. Design: This was a descriptive exploratory study. Sample and setting: 340 pregnant women recruited from two MCH centers, were selected randomly between March and June 2011, which took place in the north region of Jordan. Data collection: A structured interview questionnaire form, consisting mostly of closed questions, was developed to collect needed data. Results: The study revealed a good degree of awareness about normal signs associated with pregnancy, and to a less extent about abnormal signs. The commonest complaints of the studied group during their pregnancy were nausea and vomiting, fatigue, back pain, heartburn and vaginal discharge. The use of home remedies for these signs was high. Conclusion: The study recommended the need to include information about abnormal signs of pregnancy by health care providers, particularly the maternity nurses and midwives as a routine care during antenatal visits.
\end{abstract}

Key words: Awareness, Home Remedies, Pregnancy, Jordan

\section{Introduction:}

Pregnancy is that wonderful period in a woman's life when she spends each and every day in pleasant anticipation, waiting to hold bundle of joy in her arms at the end of the pregnancy. All women need health care and attention during pregnancy. This care helps pregnant women to be healthier and have fewer problems in birth. Prenatal care should come from the woman herself, from her family and the community, and from a midwife. On the other hand, pregnancy is usually normal and healthy, so people may not think that prenatal care is important but most midwives know that women who have good care during pregnancy are more likely to have safer births and healthier babies ${ }^{(1)}$.

During pregnancy a woman's body changes. These changes can sometimes be uncomfortable, but most of the time they are normal ${ }^{(2)}$. Abnormal signs and symptoms may lead to serious complications like morning sickness may develop into hyperemesis graviderum. So, make the mother as alert as possible for any complications that are likely to arise ${ }^{(2)}$. A recent summary of maternal causes of death, data available from a large number of low and middle-income countries included hemorrhage (25\%), infection/sepsis (15\%), high blood pressure $(12 \%)$, obstructed and /or prolonged labor $(8 \%)$ and others $(8 \%){ }^{(3,4)}$.

Developing a better understanding of how women manage these discomforts during pregnancy is a clear need as some women use home remedies that may have potential side effects for the mother and fetus ${ }^{(5,6)}$.

Obstetric nurse /midwife plays a crucial role in promoting an awareness of the public health issues for the pregnant women and her family, as well as helping for the pregnant women and her family, to recognize abnormal signs and symptoms of pregnancy, and where to seek medical assistance.

The aim of this study was to determine pregnant mothers' awareness regarding normal and abnormal signs of pregnancy. In addition, identify methods used by pregnant women to mange pregnancy complaints during current pregnancy.

\section{II.1. Research questions}

\section{Methodology}

Are pregnant women aware of normal and abnormal signs of pregnancy?

\section{II.2. Research method/design}

The current study is a quantitative exploratory descriptive study that was used to evaluate the current research problem.

\section{II.3. Research setting}

This study was conducted at the two Maternal and Child Health Care Centers (MCHC) located in the capital of Jordan, Amman and selected randomly namely Abu-Nusaar and El-Shafa. These centers are community 
health resources that provide reproductive health services (antenatal \& postnatal care), as well as they open five days weekly from 8.00 a.m. to 2.00 p.m.; where the services provided are free of charge.

\section{II.4. Scope of the study}

The study carried out in the antenatal clinic of $\mathrm{MCH}$ centers, and on women of childbearing age, between the ages of 17 and 49 years.

\section{II.5. Research population and sampling}

A purposive "non-probability" sample, consisting of all pregnant women (340) with gestational age of at least 3 months, who attend antenatal clinics for tetanus toxoid immunization and/or pregnancy follow up at the time of data collection from the previously mentioned MCH centers between March and June 2011 was enrolled in the study.

\section{II.6. Exclusion criteria}

7.1. Pregnant women who developed complications during the course of the study.

7.2. Medical and paramedical professionals are excluded.

\section{II.7. Data collection}

After an extensive review of relevant literature and previous studies, a structured interview questionnaire was developed (Arabic language) by the researcher to collect the necessary information. The content validity was tested by a jury from five experts in the nursing field. The questionnaire included the following:

1- Socio-demographic characteristics (age, education, occupation, family income, family size, etc.).

2- Obstetric history (gravidity, parity, number of living children, types of previous delivery).

3- Questions related to woman's' awareness about normal and abnormal signs of pregnancy and practices to relieve the current pregnancy complaints.

The questionnaire was tested with 30 pregnant women at MCHC in Amman to check applicability and clarity of the items. After conducting the pilot study, minor necessary changes were done mainly in the form of rephrasing some sentences and changing some terms. The tool was then finalized. The pilot sample was not included in the main study sample. The time of completing the questionnaire was 20-25 minutes.

\section{II.8. Field work}

Pregnant women were chosen according to the previously mentioned criteria. The aim of the study was explained to each of them to gain her trust. Data collected via face-to-face interview from March 2011 through June 2011. The MCHC visits were done two days/week from 9.00 a.m. to 2.00 p.m. Each interview was completed within 20-25 minutes. The form was reviewed immediately after data collection to ensure completeness.

\section{II.9. Ethical and administrative considerations}

A formal letter from the Director of Zarqa University, Zarqa, Jordan, was submitted to the Health Directors of the previously mentioned settings in order to get permission for carrying out the study in the selected centers.

The questionnaire was administered to the women personally through face-to-face interview. Instructions were provided to the participants if needed. All women joined the study voluntarily and an informed verbal consent was taken from each participant. Respondents were assured about anonymity and confidentiality of information to ensure honest response and no woman refused to participate in the study.

\section{II.10. Procedure for data analysis}

The collected quantitative data were coded, entered, and analyzed using the Statistical Package for Social Science (SPSS) program for Windows, version 11.0. 


\section{Results}

TABLE -1 Socio-demographic and obstetrical history of the participants $(n=340)$

\begin{tabular}{|c|c|c|}
\hline Items & Frequency & Percentage \\
\hline $\begin{array}{l}\text { 1- Age in years: } \\
<20 \\
20-<30 \\
30-<40 \\
40+\end{array}$ & $\begin{array}{c}19 \\
222 \\
92 \\
7\end{array}$ & $\begin{array}{c}5.5 \\
65.3 \\
27.1 \\
2.1\end{array}$ \\
\hline $\begin{array}{l}\text { 2- Education level: } \\
\text { Less than secondary school } \\
\text { Secondary school } \\
\text { Above secondary school (university/ college) }\end{array}$ & $\begin{array}{c}90 \\
110 \\
140 \\
\end{array}$ & $\begin{array}{l}26.5 \\
32.3 \\
41.2\end{array}$ \\
\hline $\begin{array}{l}\text { 3- Job status: } \\
\text { Employed } \\
\text { Unemployed }\end{array}$ & $\begin{array}{c}81 \\
259 \\
\end{array}$ & $\begin{array}{l}23.8 \\
76.2 \\
\end{array}$ \\
\hline $\begin{array}{l}\text { 4- Annual family income: } \\
\leq 200 \text { JD } \\
201-400 \text { JD } \\
>400 \text { JD }\end{array}$ & $\begin{array}{c}112 \\
161 \\
67 \\
\end{array}$ & $\begin{array}{l}32.9 \\
47.4 \\
19.7\end{array}$ \\
\hline $\begin{array}{l}\text { 5- Intended family: } \\
\text { No } \\
\text { Yes }\end{array}$ & $\begin{array}{l}233 \\
107 \\
\end{array}$ & $\begin{array}{l}68.5 \\
31.5\end{array}$ \\
\hline $\begin{array}{l}\text { 6- Family size: } \\
\leq 2 \\
3- \\
5+\end{array}$ & $\begin{array}{c}11 \\
217 \\
112\end{array}$ & $\begin{array}{l}3.2 \\
63.9 \\
32.9\end{array}$ \\
\hline $\begin{array}{c}\text { 7- No. of pregnancies: } \\
\text { Primigravida } \\
1-3 \text { times } \\
4-5 \text { times } \\
\geq 6 \text { times }\end{array}$ & $\begin{array}{c}97 \\
146 \\
61 \\
36\end{array}$ & $\begin{array}{l}28.5 \\
42.9 \\
17.9 \\
10.6\end{array}$ \\
\hline $\begin{array}{l}\text { 8- No. of abortions: } \\
\text { None } \\
\text { Less than } 3 \text { times } \\
\geq 3 \text { times }\end{array}$ & $\begin{array}{c}244 \\
59 \\
37\end{array}$ & $\begin{array}{l}71.8 \\
17.3 \\
10.9\end{array}$ \\
\hline $\begin{array}{l}9-\text { Gestational age: } \\
1^{\text {st }} \text { trimester } \\
2^{\text {nd }} \text { trimester } \\
3^{\text {rd }} \text { trimester }\end{array}$ & $\begin{array}{c}61 \\
82 \\
197\end{array}$ & $\begin{array}{l}17.9 \\
24.2 \\
57.9\end{array}$ \\
\hline $\begin{array}{l}\text { 10- Previous delivery place }(\mathrm{n}=240) \text { : } \\
\text { Public hospital } \\
\text { Private hospital/clinic } \\
\text { Home }\end{array}$ & $\begin{array}{c}128 \\
102 \\
10\end{array}$ & $\begin{array}{l}53.3 \\
42.5 \\
4.2\end{array}$ \\
\hline
\end{tabular}

The background characteristics of the pregnant women are presented in table (1). It can be noticed that almost two thirds of the study sample $(65.3 \%)$ were in the age group $20-<30$ years. As regards educational level, more than quarter $(26.5 \%)$ of the study sample were less than secondary educations, while above secondary education had the highest frequency $(41.2 \%)$. Three quarters of the study sample $(76.2 \%)$ were unemployed. Regarding family income, the same table also revealed that only $19.7 \%$ of the study group had annual family income more than $400 \mathrm{JD}$. Only $31.5 \%$ of the study sample had intended family and less than one third of them (32.9\%) had family size larger than 5.

As regards obstetrical history, the same table shows that less than one third of the sample $(28.5 \%)$ were primegravida. The mean gravidity was $2.1 \pm 1.03$. Additionally, $28.2 \%$ of the mothers had a history of previous abortion. In addition, the same table showed that the most common place of delivery was public hospitals, for $53.3 \%$ and only ten mothers $(4.2 \%)$ delivered at home in previous deliveries.

TABLE-2 Normal pregnancy symptoms as viewed by the participants $(n=340)$.

\begin{tabular}{|l|c|c|}
\hline Symptoms & Frequency & Percent \\
\hline Fainting/ dizziness & 38 & 11.2 \\
\hline Nausea and vomiting & 278 & 81.8 \\
\hline Heartburn & 233 & 68.5 \\
\hline Constipation & 159 & 46.8 \\
\hline Varicose veins & 92 & 27.1 \\
\hline Piles & 47 & 13.8 \\
\hline Leg cramp & 115 & 33.8 \\
\hline Fatigue & 287 & 84.4 \\
\hline Back pain & 249 & 73.2 \\
\hline Vaginal discharge with no itching & 230 & 67.6 \\
\hline
\end{tabular}




\begin{tabular}{|l|c|c|}
\hline Change of defecation & 72 & 21.2 \\
\hline Abdominal cramp & 176 & 51.8 \\
\hline Do not know & 28 & 8.2 \\
\hline
\end{tabular}

N.B.: More than one symptom reported by the studied sample as normal during pregnancy.

Table (2) shows awareness of the study group about normal symptoms of pregnancy. The majority (81.8\%) of the sample considered nausea and vomiting as normal symptoms during pregnancy. Less than three quarters of the sample $(73.2 \%)$ viewed back pain as normal associates of pregnancy. Almost two thirds of them $(68.5 \%$ \& $67.6 \%)$ viewed heart burn and vaginal discharge with no itching while slightly more than half $(51.8 \%)$ viewed abdominal cramp as normal symptoms during pregnancy.

Other symptoms that have been viewed as normal pregnancy include leg cramp (33.8\%), varicose veins $(27.1 \%)$, piles $(13.8 \%)$ and change of defecation $(21.2 \%)$.

Only twenty-eight $(8.2 \%)$ of the mothers did not know of any symptoms considered normal during pregnancy.

TABLE-3 Abnormal pregnancy signs and symptoms needing medical consultation as viewed by the pregnant women in the study sample $(n=340)$.

\begin{tabular}{|l|c|c|}
\hline Abnormal signs and Symptoms & Frequency $\mathrm{n}=340$ & Percent \\
\hline 1. Headache & $\mathbf{1 9 5}$ & $\mathbf{5 7 . 4}$ \\
Mild & 30 & 8.8 \\
Severe \& repeated & 165 & $\mathbf{7 2 . 7}$ \\
\hline 2. Leakage of amniotic fluid & $\mathbf{2 4 7}$ & $\mathbf{8 8 . 8}$ \\
& & 57.6 \\
\hline 3. Vaginal bleeding (n= 301) & $\mathbf{3 0 1}$ & 14.4 \\
Spotting & 196 & 16.8 \\
Small amount & 49 & $\mathbf{7 3 . 8}$ \\
large amount & 56 & 11.5 \\
\hline 4. Vaginal discharge ( $\mathbf{n}=\mathbf{2 5 1})$ & $\mathbf{2 5 1}$ & 16.8 \\
Mild without odor or itching & 39 & 45.1 \\
Copious without odor or itching & 57 & $\mathbf{4 4 . 1}$ \\
Mild or copious, with odor or itching & 155 & $\mathbf{3 0 . 0}$ \\
\hline 5. Vomiting & $\mathbf{1 5 0}$ & $\mathbf{5 7 . 7}$ \\
\hline 6. Constipation & $\mathbf{1 0 2}$ & $\mathbf{7 7 . 0}$ \\
\hline 7. Urinary Problems & $\mathbf{1 9 6}$ & 13.2 \\
\hline 8. Abdominal pain (n= 262 ) & $\mathbf{2 6 2}$ & 11.2 \\
Mild \& not continuous & 45 & 18.8 \\
Mild \& continuous & 38 & 33.8 \\
Sever \& not continuous & 64 & $\mathbf{3 3 . 5}$ \\
Sever \& continuous & 115 & $\mathbf{6 2 . 7}$ \\
\hline 9. Dizziness & $\mathbf{1 1 4}$ & $\mathbf{7 5 . 6}$ \\
\hline 10. Hypotension & $\mathbf{2 1 3}$ & $\mathbf{3 5}$ \\
\hline 11 Hypertension & $\mathbf{2 5 7}$ & $\mathbf{7 0 . 8}$ \\
\hline 12. Dyspareunia & $\mathbf{1 1 9}$ & 18.5 \\
\hline 13. Edema & $\mathbf{2 4 1}$ & 18.2 \\
Face & 63 & 34.1 \\
Lower limbs & 62 & 116 \\
\hline Whole body & & \\
\hline
\end{tabular}

N.B.: Answers are not mutually exclusive.

Table (3) shows the awareness of studied group regarding the abnormal signs and symptoms during pregnancy that needs to seek medical consultation. The table revealed that the majority $(88.8 \%)$ of participants identified the vaginal bleeding as an abnormal symptom that needs medical consultation, followed by abdominal pain (77.0\%). The third and fourth frequently reported symptoms were vaginal discharge and leakage of amniotic fluid reported by $73.8 \%$ and $72.7 \%$ of the participants respectively, even if the discharge is mild without odor or itching reported by $11.5 \%$. As well, lower limb edema wsa reported by less than fifth of the participants $(18.2 \%)$, while more than half $(57.4 \% \& 57.5 \%)$ considered headache and urinary problems respectively during pregnancy need medical consultation. Also, out of the 195 (57.4\%) mothers who considered headache needs medical consideration, $8.8 \%$ mentioned mild headache as considered abnormal symptoms during pregnancy.

The same table revealed that of $241(70.8 \%)$ of mothers who mentioned edema as abnormal symptoms of pregnancy, $18.2 \%$ considered lower limb edema during pregnancy needs medical consultations. Other symptoms reported by about one third of the participants in the study include constipation (30.0\%), dizziness (33.5\%), and dyspareunia (35.0\%). 
TABLE-4 Current pregnancy complaints and its management among the pregnant women in the study sample $(\mathbf{n}=\mathbf{3 4 0})$.

\begin{tabular}{|c|c|c|c|}
\hline \multirow[t]{2}{*}{ Complaints } & \multicolumn{3}{|c|}{ Management } \\
\hline & Nothing $\%$ & Medical Advice \% & Home Remedies \% \\
\hline 1- Leg cramp $(n=75)$ & 24.0 & 29.3 & 46.7 \\
\hline 2- Nausea \& vomiting $(n=56)$ & 05.4 & 21.4 & 73.2 \\
\hline 3- Low back pain $(n=38)$ & 26.3 & 00.0 & 73.7 \\
\hline 4- Heart burn $(n=37)$ & 08.1 & 10.8 & 54.1 \\
\hline 5- Lucorrhoea $(n=29)$ & 17.2 & 51.7 & 31.1 \\
\hline 6- Constipation $(n=26)$ & 00.0 & 34.6 & 65.4 \\
\hline 7- Headache $(n=24)$ & 08.3 & 66.7 & 25.0 \\
\hline 8 - Fatigue $(n=16)$ & 62.5 & 37.5 & 00.0 \\
\hline 9-Dyspnea $(n=12)$ & 16.7 & 33.3 & 50.0 \\
\hline 10- Hypertension $(n=9)$ & $00.0 \%$ & 44.4 & 55.6 \\
\hline 11-Piles $(n=8)$ & 12.5 & 37.5 & 50.0 \\
\hline 12- Breast problems $(\mathrm{n}=3)$ & 00.0 & 33.3 & 66.7 \\
\hline 13- others $(n=10)$ & 00.0 & 30.3 & 69.7 \\
\hline
\end{tabular}

N.B.:

- Number of mothers having complaints during current pregnancy (333)

- Participants reported more than one complaint during current pregnancy.

Table (4) presents that, the most common complaints during the current pregnancy is leg cramps (75 women), followed by nausea and vomiting (56 women), only 3 women complained breast problems during current pregnancy. As regards management of the current complaints relatively high percentages of mothers used home remedies to manage low back pain, nausea and vomiting, breast problems, and constipation $(73.7 \%$, $73.2 \%, 66.7 \% \& 65.4 \%$ ) respectively.

\section{Discussion}

Awareness of abnormal signs of obstetrics complications during pregnancy is the first essential step for appropriate and timely referral. The finding of this study has provided insight information on women's awareness about normal and abnormal signs of pregnancy and practices used to relieve the current complaints.

The awareness of pregnant women, about normal signs of pregnancy in the present study, the majority of pregnant women mentioned nausea and vomiting, back pain, vaginal discharge, heartburn as normal signs associated with pregnancy. Meanwhile, only a minority of them did not know of any normal signs associated with pregnancy. This is generally in line with a study carried out in Egypt. The researcher found that, the majority of pregnant women consider nausea and vomiting, dizziness, fainting and back pain as a normal signs during pregnancy ${ }^{(7)}$.

This could be attributed to the fact that many women did not identify certain signs and symptoms with pregnancy, but instead with normality making the symptoms less serious in their eyes, which indicates a need for appropriate health education and services. Awareness about the significance of abnormal symptoms and signs of pregnancy may lead to timely access to appropriate emergency obstetric care.

In this study, the majority of the pregnant women mentioned vaginal bleeding as abnormal symptoms associated with pregnancy, which is much higher than the findings in Burkina Faso (39.4\%) and Guatemala $(31.0 \%)^{(8,9)}$. This difference might be due to socio-cultural difference. and difference in implementation of relevant health intervention programs.

Evidence shows that the major causes of maternal mortality to be hemorrhage, sepsis, and hypertensive disorder of pregnancy and pregnant mothers need to have adequate knowledge about the signs indicating these problems ${ }^{(10)}$. In the current study, results revealed that minorities representing less than tenth and fifth of pregnant women mentioned mild headache and lower limb edema are considered abnormal signs during pregnancy. This finding is consistent with other studies carried out in Kenya and Jordan about lack of awareness of pregnancy danger signs ${ }^{(10,11,12)}$.

During pregnancy, women may experience one or more of wide variety of discomforts. Most discomforts experienced during pregnancy are thought to be the result of abundant hormonal changes. Other discomforts are attributed to physical changes associated with the enlarging uterus ${ }^{(13)}$.

The present study indicated that out of the 340 mothers in the sample, most of them had some complaints of physical discomfort during their current pregnancy. The most frequently discomforts experienced by the studied group were leg cramp, nausea and vomiting and low back pain. This is in agreement with the result of the study was conducted on 193 pregnant women in Canada, the finding reported that, 130 of 193 $(67.4 \%)$ of women experiencing nausea and vomiting ${ }^{(14)}$. In an other longitudinal study conducted in Portugal on 49 pregnant women, reported that $71.4 \%$ and $91.7 \%$ of women had back pain at 12 weeks and at 37 weeks of pregnancy ${ }^{(15)}$. In the present study, heartburn was the presenting complaints in relatively high percentage 
representing more than two thirds. This present study finding was higher in comparison to previous prospective research conducted in Brazil, which mentioned that, heartburn occurred in $63 \%$ of the pregnant women. This difference in the results may be due to ingested high amount of polyunsaturated fatty acid ${ }^{(16) .}$ However, it seems that the heartburn is associated with dietary fat intake.

For all types of complaints, there are many home remedies for treating these complaints much more frequently used when compared to seeking medical advice. Many women do not seek medical help because of the fear of child being affected. These findings are in agreement with the results of similar studies in Jordan in 2007 and 2012 , the researchers reported that the majority of pregnant women ( $62 \%$ \& $55.3 \%$ respectively) delayed in seeking care ${ }^{(17,18)}$. In another study, $26.1 \%$ of pregnant women reported that home remedies were not harmful as medication use during pregnancy ${ }^{(19)}$. In addition, Egyptian pregnant mothers used home remedies more than seeking medical advice in year $2000^{(20)}$.

In a more recent study, which stated that, Jordanians old age pregnant mothers, low income, and women who were not employed are more likely to use home remedies to manage heartburn during pregnancy than other groups. ${ }^{(21)}$. They added that, socioeconomic status, extended family size, health beliefs, access and level of trust in available local medical care might have affected the decision to seek medical care.

\section{Conclusion and recommendations}

Based on the findings of the current study, it can be concluded that, lack of awareness about abnormal signs of pregnancy regarding pregnant women attending the antenatal care in Amman, Jordan, led to that the use of home remedies for current complaints during pregnancy was high.

Therefore, this study reflects the needs for strategic plan to increase the awareness to shape healthseeking behaviors of the pregnant women related to normal and abnormal signs of pregnancy, and create awareness on home remedies. The health care providers, particularly the nurses and midwives need to have a more active role in educating pregnant women and in advising them about normal and abnormal signs of pregnancy. The study can be replicated on a larger sample and investigate the factors affecting level of awareness of signs of pregnancy.

\section{Limitation}

A prospective "non-probability" sampling technique does not give a representative sample.

\section{References:}

[1] S. Miller and F. Thomson. A book for midwives: Care for pregnancy, birth, and Women's health $2^{\text {nd }}$ ed., (the Hesperian Foundation Berkeley, California, USA.2010). 1-28

[2] B.T. Basavantappa , Midwifery and Reproductive Health Nursing $1^{\text {st }}$ ed. (New Delhi: Jaypee Brother; 2005). 171, 232, 254.

[3] The United States' Global Role CSIS: Improving maternal mortality and other aspects of women's health, Phillip Nieburg,2012,October,1-20.Available at csis.org/.../121003_Nieburg_MaternalMortality_Web.pd.

[4] M. Rahman and J. Menken, Reproductive health in global health: Diseases, programs, systems and policies , $3^{\text {rd }}$, edited by Michael H. Merson, Robert E ,Anne J Mills (Burlington, MA Jones and Bartlett). 2012, 115-176.

[5] J.E. Richter, Gastroesophageal reflux disease during pregnancy. Gastroenterology Clinics of North America,32, $2003,235-261$.

[6] J.E. Richter, Review article: the management of heartburn in pregnancy. Alimentary Pharmacology and Therapeutics, 22, 2005, 749-757.

[7] M.F. Heba, Home remedies used to relive pregnancy-related complaining among expectant mothers in Al-Salam district in Port Said, Unpublished master's diss.; Faculty of Nursing, Suez Canal University. Egypt, 2001.

[8] B.Baya, G. Sangli, and A. Maiga, Measuring the effects of behavior change interventions in Burkina Faso with population-based survey results. Maryland, USA: JHPIEGO, 2004.

[9] F. Becker, C. Yglesias, Measuring the effects of behavior change and service deliver interventions in Guatemala with populationbased survey. Maryland, USA: JHPIEGO, 2004.

[10] C. Warren, and W. Liambila, Approaches to providing quality maternal care in Kenya: Safe motherhood demonstration project, western province, Nairobi, Kenya: Ministry of Health, Kenya and University of Nairob.

[11] J.C Fotso, What does access to maternal care mean among the urban poor? Factors associated with use of appropriate maternal health services in the slum settlements of Nairobi, Kenya. Maternal and Child Health Journal,13, 2009,:130-137.

[12] A. Okour, M. Alkhateeb, and Z. Amarin, Awareness of danger signs and symptoms of pregnancy complication among women in Jordan. International Journal of Gynecology and obstetrics, 118(1), 2012, 11-14.

[13] E. Sakornbut, Medical care and pregnancy: Common preconception and antepartum issues, in J.A.Rosenfeld, Handbook of women's health: an evidence-based approach, (Cambridge. United Kingdom, 2001) 206-226.

[14] S. Emelianova, P. Mazzotta, A. Einarson, and G. Koren, Prevalence and severity of nausea and vomiting of pregnancy and effect of vitamin supplementation. [online], 1999, 106-09. Available from URL: http//ww.nvp-volumes.orgp2-3htm.

[15] C. Quaresma, C. Silva, M.F. Secca, J.G. O'Neill, Back pain during pregnancy: a longitudinal study. Acta Reumatol Port, [online], 35(3), 2010, 346-51. Available from: URL: http//www.ncbinlm nih gov/pubmed/209.75638.

[16] V. Doll'Alba, F. Fomari, C. Krahe, S.M. Callegari-Jacque, and S.G. Silva de Barros, Heartburn and regargitation in pregnancy: The effect of fat ingestion. Dig Dissic. [online], (55(6), 2010, 1035-39. Available from: URL:http//heartburnresearchtoday.net/.

[17] Essential obstetric care clinical guidelines for physicians: Health systems strengthening, Amman, Ministry of Health Jordan,2007.

[18] A.M. Okour, Y. Khader, Z. Amarin, H. Jaddou,and M. Gharaibeh, Maternal mortality in Jordan: role of substandard care and delays. Eastern Mediterranean Health Journal, 18(5), 2012, 426-431.

[19] H.A. Amasha, S.S. Jarrah. The use of home remedies by pregnant mothers as a treatment of pregnancy related complaints: An exploratory study. The Medical Journal of Cairo University, 80(1), 2012, 674-680. 
[20] L.A. Hassan, Assessment of pregnant women's knowledge and practices toward minor discomforts during the third trimester of pregnancy at Port Said City, unpublished master's diss; Faculty of Nursing, Suez Canal University, Egypt, 2000.

[21] R. Khresheh, Strategies used by Jordanian women to alleviate heartburn during pregnancy. Midwifery, 2010. Available at: 1016/j.midw.2010.05.013. 